\title{
Determinants of subjective novelty
}

D. E. BERLyne AND L. C. C. PARHAM

UNIVERSITY OF TORONTO

Subjects were exposed to sequences of colored shapes and required to rate each stimulus on a 7-point scale for "novelty." The sequences were such that 12 hypotheses regarding determinants of subjective novelty could be tested by orthogonal comparisons. The results of two experiments confinmed eight of the hypotheses.

The motivational effects of stimulus properties like novelty and complexity have been attracting a great deal of attention during the last 20 years. This is largely because of the strong influence of these properties on exploratory behavior and the orientation reaction. But their important bearing on other psychological phenomena is also coming to be acknowledged (Berlyne, 1960, 1963, 1966). Since properties of this kind depend on comparison or collation of two or more stimulus elements, the term "collative property" has been proposed for them (Berlyne, 1960).

Collative stimulus properties are clearly quantitative. They can occur in varying degrees, and affective reactions often hinge quite delicately on the precise degree to which they are present. For example, there must generally be just the right amount of novelty or complexity if a work of art or a joke is to be successful. But the measurement of these properties raises problems because of their complex relations with physico-chemical and statistical attributes of stimulus patterns. In some conditions, the concepts of information theory can help, but these concepts are not sufficient to dispose of the problems completely (Berlyne, 1957, 1960).

Collative stimulus properties are subjective in the sense that they depend jointly on attributes of stimulus patterns and the present state of S. A common recourse when faced with subjective variables that bear complex relations to physical stimulus properties is to apply scaling procedures to verbally expressed judgments. This bolls down to finding out how ordinary people use the words denoting the properties in question. Anatomical variables (Volkmann \& Stevens, 1940), neurophysiological variables (Granit, 1935), and nonverbal behavior of animals (Blough, 1966) have often been found to bear simpler relations to subjective scales derived from human verbal responses than to physical scales.

Several investigators (Attneave, 1957; Goldstein, 1961; Karmel, 1966; Berlyne, McDonnell, Ntcki, \& Parham, 1967; Day, 1967) have used scaling techniques to identify determinants of judged complexity.

In the two experiments reported in the present article, an attempt was made to do the same for judged novelty.

The definition and measurement of novelty present special difficulties. The word "novelty" is commonly bandied about in psychological and neurophysiological literature with scant attention to the need for specifying exactly what it denotes. There are several different senses in which something can be novel (Berlyne, 1955, 1960). The essentially empirical question of how the variables corresponding to these senses may be related has generally been neglected, and novelty is all too often confused with other properties, such as change, surprisingness, and incongruity (Berlyne, 1960, ch. 2). Most of the standard psychophysical methods cannot be applied to novelty; they generally require stimuli to be presented repeatedly, often with a frequency or duration depending on S's responses, and repetition and prolongation will clearly alter degree of novelty. The usual paired-comparison techniques cannot be used, since the novelty of a stimulus must vary with what has preceded it, and

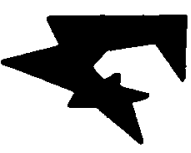

1

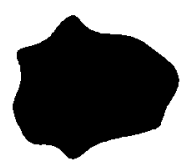

3

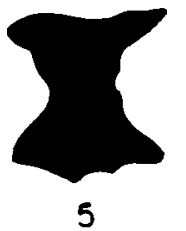

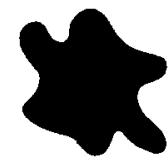

2

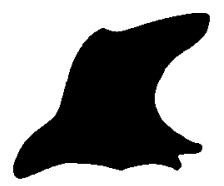

4

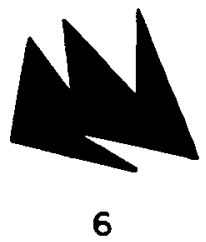

Fig. 1. Shapes used in Experiment 1. 
it is hardly possible to pair two stimuli that have just been preceded by different stimulus sequences. So a simple rating procedure seems indicated and was adopted for the experiments to be reported.

\section{Subjects}

\section{EXPERIMENT I}

Eighty undergraduates taking psychology courses, 40 males and 40 females, served as Ss. At the end of the experiment, they were tested for color blindness with the American Optical Co. H-R-R Pseudochromatic plates. Five additional Ss were eliminated, three because of color blindness and two because of apparatus failure.

\section{Stimulus material}

The six shapes in Fig. 1 were presented in various colors, as explained below. The first five were taken from Berlyne and Lawrence (1964) and the sixth from Vanderplas and Garvin (1959)

\section{Procedure}

The $S$ was first required to learn the following numerical scale: 7-very novel; 6-quite novel; 5slightly novel; 4-neither novel nor familiar; 3slightly familiar; 2-quite familiar; 1-very familiar. He was tested for ability to supply the number corresponding to each judgment and vice versa. After both $\mathrm{S}$ and $\mathrm{E}$ were satisfied that the scale had been mastered, the room was darkened, and the experiment began. It consisted of two phases, during each of which a sequence of 14 colored shapes was projected on a screen. Each stimulus appeared for 9 sec. A blank slide was projected for 9 sec between the two phases while $E$ announced, "Another series will follow immediately after this." During the exposure of each stimulus, $S$ had to assign a degree of novelty-familiarity to it and utter the corresponding number.

\section{Sequence classes and hypotheses}

Eight classes of sequence were used. They were as follows (subscripts attached to the same letter representing successive appearances of the same stimulus):

(1) $\begin{array}{lllllllllllllllllllll}Y_{1} & Y_{2} & Y_{3} & Y_{4} & Y_{5} & Y_{6} & Y_{7} & Y_{8} & x_{1} & Y_{9} & Y_{0} & Y_{1} & Y_{2} & \underline{X}_{L}\end{array}$

(2) $\begin{array}{llllllllllllllll}Y_{1} & Y_{2} & Y_{3} & Y_{4} & \underline{X}_{1} & Y_{5} & Y_{6} & Y_{7} & Y_{8} & Y_{9} & Y_{0} & Y_{11} & Y_{2} & \underline{X}_{L}\end{array}$

(3) $\begin{array}{lllllllllllllllllll}\underline{X}_{1} & Y_{1} & Y_{2} & \underline{X}_{2} & Y_{3} & Y_{4} & \underline{X}_{3} & Y_{5} & Y_{6} & Y_{7} & Y_{8} & Y_{9} & Y_{0} & \underline{X}_{L}\end{array}$

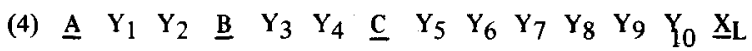

In sequence classes (1)-(4), all stimuli were of the same shape, but those denoted by different letters differed in color. Sequence classes (1'), (2'), (3'), and (4') resembled classes (1), (2), (3), and (4), respectively, but stimuli denoted by different letters differed in both shape and color.

These eight sequence classes permitted eight hypotheses to be tested by mutually orthogonal comparisons, as follows. (The numbers in parentheses denote sequence classes, and the sign ">" means "is rated more novel than." Thus " $\mathrm{X}_{\mathrm{L}}(2,2$ ') $>\mathrm{X}_{\mathrm{L}}\left(1,1^{\prime}\right)^{\prime \prime}$ means that the mean novelty rating of the final stimulus $\left(X_{L}\right)$ in sequence classes (2) and (2') will be greater than the mean rating of the final stimulus $\left(X_{L}\right)$ in sequence classes (1) and (1*).)

Hypothesis 1. The subjective novelty of a stimulus will increase with the time elapsing since the last appearance of that stimulus: $x_{L}\left(2,2^{\prime}\right)>X_{L}$ (1, 1').

Table 1. Experiment 1

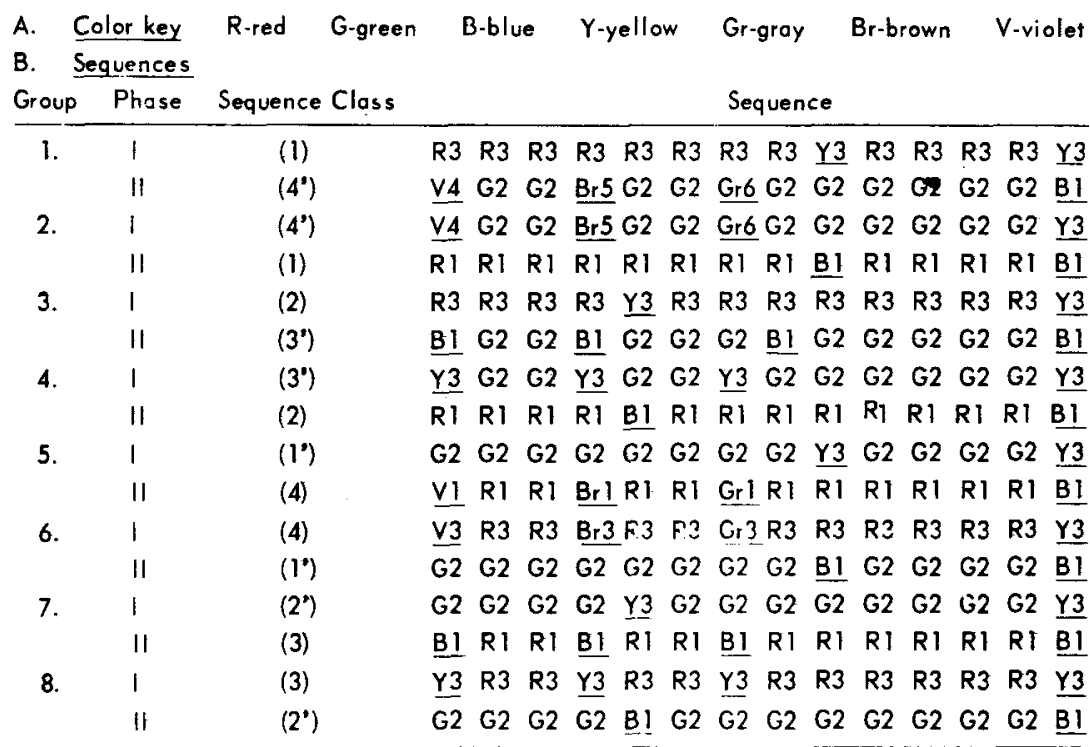


Hypothesis 2. The subjective novelty of a stimulus will vary inversely with the number of times that an identical stimulus has appeared in the recent past: $X_{L}\left(1,1^{\prime}, 2,2^{\prime}\right)>X_{L}\left(3,3^{\prime}\right)$.

Hypothesis 3. The subjective novelty of a stimulus will be less if it has appeared one or more times in the recent past than if it has not: $\mathrm{X}_{\mathrm{L}}\left(4,4^{\prime}\right)$ $>\mathrm{X}_{\mathrm{L}}\left(1,1^{\prime}, 2,2^{\prime}, 3,3^{\prime}\right)$.

Hypothesis 4 . The subjective novelty of a stimulus will increase with the number of attributes distinguishing it from other stimuli that have preceded it in the recent past: $\mathrm{X}_{\mathrm{L}}\left(1^{\prime}, 2^{\prime}, 3^{\prime}, 4^{\prime}\right)>\mathrm{X}_{\mathrm{L}}$ $(1,2,3,4)$.

Hypothesis 5. The subjective novelty of a stimulus on its first appearance will increase with the number of repetitions of another stimulus that have preceded it: $X_{1}\left(1,1^{\prime}\right)>X_{1}\left(2,2^{\prime}\right)$.

Hypothesis 6 . The subjective novelty of a stimulus will be less on its second appearance within a short period than on its first appearance: $X_{1}\left(1,1 ', 2,2^{\prime}\right)$ $>\mathrm{X}_{\mathrm{L}}\left(1,1^{\prime}, 2,2^{\prime}\right)$.

Hypothesis 7 .

When a stimulus appears intermittently, interspersed with appearances of another stimulus, subjective novelty will decline more quickly than when heterogeneous stimuli appear with the same temporal distribution: there will be a steeper downward trend for the non-Y items of sequence classes (3) and (3') than for those of (4) and (4'). Hypothesis 8 . Subjective novelty will decline over a succession of repetitions of the same stimulus: there will be a downward trend over the first eight $Y$ items of sequence classes (1) and (1') and also over the first four $Y$ items of sequence classes (2) and (2').

\section{Experimental design}

The 80 Ss were divided into eight groups of five men and five women. The sequence classes and

EXP.I

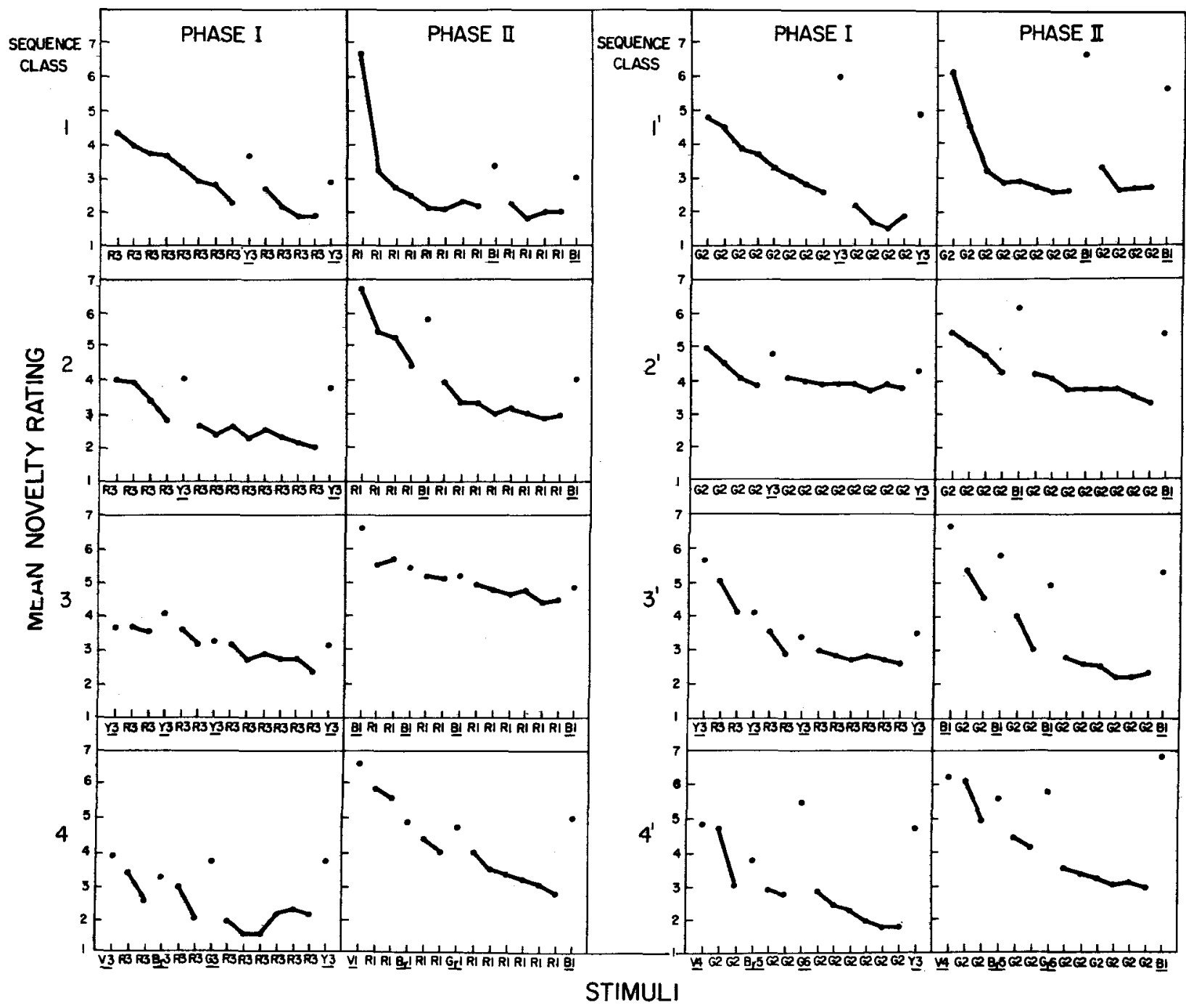

Fig. 2. Mean-novelty-rating curves from Experiment 1. 
actual sequences that the various groups had during the two phases of the experiment are shown in Table 1.

For each of the Hypotheses 1-5, this design permitted a between-Ss comparison in Phase $I$ and another between-Ss comparison, involving different Ss (who this time had just had experience of the task with another sequence), in Phase II. The comparisons pertaining to Hypotheses 6-8 were within-Ss.

\section{results}

Figure 2 presents the mean-novelty-rating curves for the 16 different sequences,

Hypotheses 1-5. Analyses of variance, with orthogonal contrasts, were carried out on the ratings of $\mathrm{X}_{\mathrm{L}}$ in Phase I and in Phase II separately. Stouffer's technique (Stouffer et al, 1949, p. 45) was also used to arrive at combined significance levels. A further analysis of variance was carried out, for each phase separately, on the ratings of $\mathrm{X}_{1}$ in sequence classes $(1),\left(1^{\prime}\right),(2)$, and $\left(2^{\prime}\right)$. The relevant means and the significant $F$ and $z$ values are shown in Table 2.

It will be seen that Hypotheses 3 and 4 were confirmed, but not Hypotheses 1, 2, and 5 .

Hypothesis 6. An analysis of variance was carried out, for each phase separately, on ratings of $X_{1}$ and $X_{L}$ in sequence classes (1), (1'), (2), and (2). The means for $X_{1}$ were significantly higher than those for $X_{L}$ both in Phase $I-$ means $=4.7,4.2$, $(F=7.63, \mathrm{df}=1 / 36, \mathrm{p}<.01)$ and Phase II-means = 5.4, $4.5(\mathrm{~F}=14.55, \mathrm{df}=1 / 36, \mathrm{p}<.001)$, confirming Hypothesis 6.

The $X$ means for (1') and (2') significantly exceeded those for (1) and (2) in both Phase $1-$ means $=5.8,3.8(\mathrm{~F}=6.59, \mathrm{df}=1 / 36, \mathrm{p}<.025)$ and Phase II - means $=5.8,4.0 \quad(F=14.93, \mathrm{df}=1 / 36, p<.001)$, so that further evidence is provided in support of Hypothesis 4. The interaction between the $\left(1,1^{\prime}\right) /$ $\left(2,2^{\prime}\right)$ and the $(1,2) /\left(1^{\prime}, 2^{\prime}\right)$ dichotomies was significant in Phase II only $(F=4.98, \mathrm{df}=1 / 36, \mathrm{p}<.05)$.

Hypothesis 7. Analyses of variance were carried out, for each phase separately, on ratings of $\mathrm{X}, \mathrm{A}$, $B$, and $C$ items in sequence classes (3), ( $\left.3^{\prime}\right),(4)$, and $\left(4^{\prime}\right)$. The prediction crucial to the hypothesis is that of a significant interaction between the $\left(3,3^{\prime}\right) /$ $\left(4,4^{\prime}\right)$ dichotomy and successive non-Y items. In accordance with the prediction, ratings declined less steeply in (4) and $\left(4^{\prime}\right)$, where the non- $Y$ items were all different, than in (3) and (3'), where they were identical (in Phase I, $F=4.19, d f=3 / 108, p<$ .05 ; in Phase 2, $F=2.87, \mathrm{df}=3 / 108, \mathrm{p}<.10$ ). Combining the $p$ values, we find that $z=2.55$ and $p<.02$. Hypothesis 7 is therefore confirmed.

Hypothesis 8. A trend analysis was carried out on the ratings of the first eight $Y$ items in sequence classes (1) and (1') for both phases together. There was a downward overall trend with significant linear and quadratic components ( $F=218.21$ and 40.88, df $=1 / 252, \mathrm{p}<.001$ in both cases). The trend did not differ significantly from (1) to (1'). But both linear and quadratic components differed significantly from Phase I to Phase II $(F=8.24$ and $33.96, d f=1 / 252$, $\mathrm{p}<.01$ and $\mathrm{p}<.001$ ). As inspection of Fig. 2 shows, ratings declined gently and rectilinearly in Phase $I$, but, in Phase II, the decline approximated a rather steep exponential decay curve.

A similar trend analysis carried out on the ratings of the first four $Y$ items in (2) and (2') reveals a downward trend with a significant linear component $(F=45.95, \mathrm{df}=1 / 108, \mathrm{p}<.001)$. But the quadratic component was not significant. Nor was there any significant interaction with phases or with the (2)/ (2') dichotomy. Mean ratings were, however, significantly higher in Phase II than in Phase $I(F=7.02$, $\mathrm{df}=1 / 36, \mathrm{p}<.01$ ).

\section{Biscussion}

Evidence has been obtained to support Hypotheses $3,4,6,7$, and 8 . Hypotheses 1, 2, and 5, however, were not confirmed, which means either that they are false or that the experiment was insufficiently sensitive to reveal the effects predicted from them.

There were some interesting and unexpected dif-

Table 2. Experiment 1

Data Relevant to Hypotheses 1-5

\begin{tabular}{|c|c|c|c|c|c|c|c|}
\hline \multirow[t]{2}{*}{ Hypothesis } & \multirow[t]{2}{*}{ Independent Variable } & \multirow[t]{2}{*}{ Stimulus } & \multicolumn{2}{|c|}{ Phase ! } & \multicolumn{2}{|c|}{ Phase I.I } & \multirow[t]{2}{*}{ Combined $z$} \\
\hline & & & Means & $F(d f=1 / 63)$ & Means & $F(d f=1 / 63)$ & \\
\hline \multirow[t]{2}{*}{1} & Time since & $x_{L}\left(1,1^{\prime}\right)$ & 4.4 & ns & 4.2 & ns & ns \\
\hline & last $x$ & $x_{L}\left(2,2^{\prime}\right)$ & 4.0 & & 4.6 & & \\
\hline \multirow[t]{2}{*}{2} & Number of & $x_{L}\left(1,1 * 2,2^{\prime}\right)$ & 4.2 & ns & 4.4 & ns & ns \\
\hline & prior $X_{s}$ & $X_{L}\left(3,3^{\prime}\right)$ & 3.3 & & 5.3 & & \\
\hline \multirow[t]{2}{*}{3} & Prior appearance & $x_{L}\left(1,1^{\prime}, 2,2^{\prime}, 3,3^{\prime}\right)$ & 3.7 & & 4.7 & & \\
\hline & of $X$ & $X_{L}\left(4,4^{\prime}\right)$ & 4.2 & ns & 5.9 & $6.49 * *$ & $2.37^{*}$ \\
\hline \multirow[t]{2}{*}{4} & Number of & $x_{L}(1,2,3,4)$ & 3.5 & & 4.2 & & \\
\hline & changed attributes & $x_{L}\left(1^{\prime}, 2^{\prime}, 3^{\prime}, 4^{\prime}\right)$ & 4.4 & $6.92 * *$ & 5.7 & $12.13 * * *$ & $4.32 * * *$ \\
\hline \multirow[t]{2}{*}{5} & Number of $Y s$ & $x_{1}(1,1)$ & 5.0 & & 5.0 & & \\
\hline & before first $X$ & $x_{1}\left(2,2^{\prime}\right)$ & 4.4 & ns & 5.9 & ns & ns \\
\hline
\end{tabular}

Two-tailed p ralues: * $p<.025, * * p<.005, * * p<.001, n s-$ not significant. 
ferences between Phases I and II in the results pertaining to the initial string of eight $Y$ items in sequence classes (1) and (1'). It seems likely that these had something to do with the experience of the task that Ss had when they had completed Phase I and approached Phase II. In particular, Ss had no way of knowing what outlandishly novel stimuli might be presented before the first phase was over. There is reason to suspect that they intended to hold the highest novelty ratings in reserve in case they were called for. They would have had less reason to do so after going through one sequence. This could have accounted for the higher mean ratings in Phase II with sequence classes (1) and (1'). It could also have produced greater flexibility in using the scale, resulting in the steeper and curvilinear decline that distinguished Phase II from Phase I in (2) and (2').

Experiment 2 was therefore undertaken to test some of the same hypotheses further, as well as some additional hypotheses. Another variable was also introduced: half of the Ss were allowed to examine a set of stimuli from which, they were told, those to be used in the experiment would be taken. This should have removed any reservations due to wondering how novel later stimuli might be. Consequently, this prefamiliarization treatment could make for higher mean ratings. On the other hand, prefamiliarization permitted effects of long-term novelty, as well as short-term novelty, to be sam- pled. It ensured that the stimuli comprising the experimental sequences had been encountered a short while before ratings were required, whereas, without it, Ss are unlikely to have seen the stimuli figuring in the experiment recently or even at all. If this factor is important, the prefamiliarization treatment can be expected generally to depress novelty ratings.

\section{EXPERIMENT 2}

\section{Subjects}

Eighty undergraduates taking summer session courses in psychology served as Ss.

\section{Procedure}

The procedure was exactly the same as in Experiment 1 except for the stimulus sequences and for the prefamiliarization treatment given to half of the Ss. Before receiving instructions for the rating task, Ss assigned to the prefamiliarization treatment were exposed to a slide showing, in color, the 18 shapes in Fig. 3. They were told that the stimuli to be used in the experiment would be taken from this set and asked to let $E$ know when they felt "reasonably well acquainted with the range of pictures shown here" and able to recognize them if they saw them again. They were allowed to examine the display until they indicated that they had seen it for long enough, whereupon instructions were given and the experiment began. The shapes

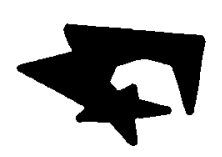

I

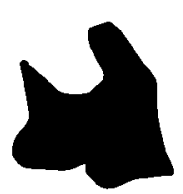

7

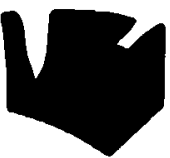

13

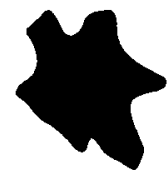

2

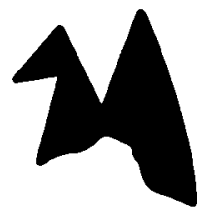

8

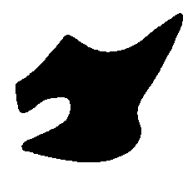

14

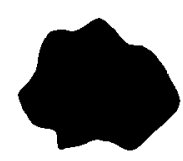

3

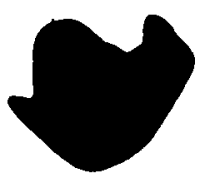

9

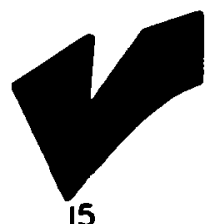

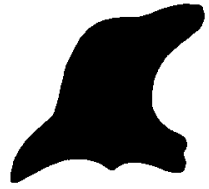

4

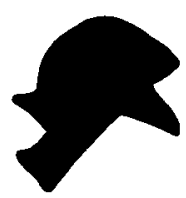

10

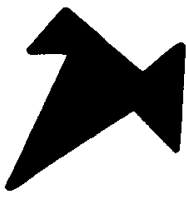

16

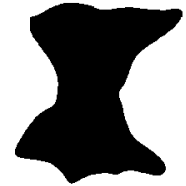

5

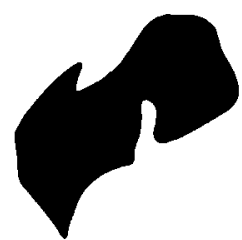

11

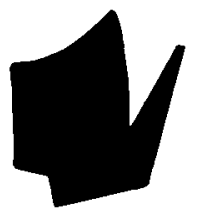

17

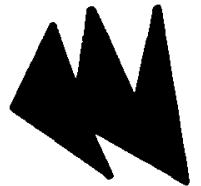

6

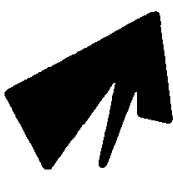

12

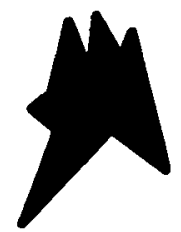

18

Fig. 3. Shapes used in Experiment 2. 
Table 3. Experiment 2

Experimental design

A. Pairing of shapes (numbered as in Fig. 3) with colors

$\begin{array}{ll}\text { 1. Red } & \text { 10. Black } \\ \text { 2. Green } & \text { 11. Light yellow } \\ \text { 3. Yellow } & \text { 12. Light Blue } \\ \text { 4. Light violet } & \text { 13. Gray-brown } \\ \text { 5. Brown } & \text { 14. Blue-green } \\ \text { 6. Gray } & \text { 15. Light brown } \\ \text { 7. Light green } & \text { 16. Dark violet } \\ \text { 8. Mouve } & \text { 17. Pink } \\ \text { 9. Gray-blue } & \text { 18. Blue }\end{array}$

B. Sequences

\begin{tabular}{|c|c|c|c|c|c|c|c|c|c|c|c|c|c|c|c|c|c|c|}
\hline Groups & Phase & Sequence class & & & & & & & que & & & & & & & & & \\
\hline \multirow{2}{*}{ IF \& INF } & l & (1) & 1 & 1 & 1 & 1 & 1 & 1 & 1 & 1 & 1 & 1 & 1 & 1 & $\underline{3}$ & 1 & 1 & $\underline{3}$ \\
\hline & II & $(2)$ & 2 & 2 & 18 & 2 & 2 & 2 & 2 & 2 & 2 & 2 & 2 & 2 & 2 & 2 & 2 & 18 \\
\hline \multirow[t]{2}{*}{$2 F \& 2 N F$} & 1 & (2) & 1 & 1 & $\underline{3}$ & 1 & 1 & 1 & 1 & 1 & 1 & 1 & 1 & 1 & 1 & 1 & 1 & $\underline{3}$ \\
\hline & II & (1) & 2 & 2 & $\overline{2}$ & 2 & 2 & 2 & 2 & 2 & 2 & 2 & 2 & 2 & 18 & 2 & 2 & 18 \\
\hline \multirow[t]{2}{*}{$3 F \& 3 N F$} & 1 & (3) & 1 & 1 & 1 & 1 & 1 & 1 & 1 & 1 & 1 & 1 & 1 & 1 & 1 & 1 & 1 & $\underline{3}$ \\
\hline & II & (4) & 2 & 4 & 5 & 6 & 7 & 8 & 9 & 10 & 11 & 12 & 13 & 14 & 15 & 16 & 17 & $1 \overline{8}$ \\
\hline \multirow[t]{2}{*}{$4 F \& 4 N F$} & 1 & (4) & 1 & 4 & 5 & 6 & 7 & 8 & 9 & 10 & 11 & 12 & 13 & 14 & 15 & 16 & 17 & $\underline{3}$ \\
\hline & II & (3) & 2 & 2 & 2 & 2 & 2 & 2 & 2 & 2 & 2 & 2 & 2 & 2 & 2 & 2 & 2 & $1 \overline{8}$ \\
\hline
\end{tabular}

were taken from the same sources as those used in Experiment 1, apart from five from Borreson and Lichte (1962).

\section{Sequence classes and hypotheses}

Four sequence classes were used as follows:

(1) $Y_{1} Y_{2} Y_{3} Y_{4} Y_{5} Y_{6} Y_{7} Y_{8} Y_{9} Y_{10} Y_{11} Y_{12} \underline{X}_{1} Y_{13} Y_{14} \underline{X}_{L}$

(2) $Y_{1} Y_{2} \underline{X}_{1} Y_{3} Y_{4} Y_{5} Y_{6} Y_{7} Y_{8} Y_{9} Y_{10} Y_{11} Y_{12} Y_{13} Y_{14} \underline{X}_{1}$

(3) $\mathrm{Y}_{1} \mathrm{Y}_{2} \mathrm{Y}_{3} \mathrm{Y}_{4} \mathrm{Y}_{5} \mathrm{Y}_{6} \mathrm{Y}_{7} \mathrm{Y}_{8} \mathrm{Y}_{9} \mathrm{Y}_{10} \mathrm{Y}_{11} \mathrm{Y}_{12} \mathrm{Y}_{13} \mathrm{Y}_{14} \mathrm{Y}_{15} \underline{\mathrm{X}}_{\mathrm{L}}$

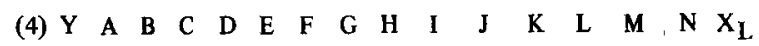

These sequence classes, presented with and without prefamiliarization, permitted the following hypotheses to be tested with orthogonal comparisons. Four of them have already figured in Experiment 1 and are therefore numbered as before. The other four are new.

Hypothesis $1 . \quad \mathrm{X}_{\mathrm{L}}(2)>\mathrm{X}_{\mathrm{L}}(1)$.

Hypothesis 3. $\mathrm{X}_{\mathrm{L}}(3,4)>\mathrm{X}_{\mathrm{L}}(1,2)$.

Hypothesis 5. $\mathrm{X}_{1}(1)>\mathrm{X}_{1}(2)$.

Hypothesis 6. $\mathrm{x}_{1}(1,2)>\mathrm{X}_{\mathrm{L}}(1,2)$.

Hypothesis 8 . There will be a downward trend over the first $12 \mathrm{Y}$ stimuli in sequence class (1).
Hypothesis 9. The subjective novelty of a stimulus will vary inversely with the number of different kinds of stimulus that have preceded it: $X_{L}(3)>$ $\mathrm{X}_{\mathrm{L}}(4)$.

Hypothesis 10. Subjective novelty will be affected by the presence or absence of prefamiliarization. As explained above, this hypothesis has to be stated in a two-sided form, since the prefamiliarization treatment could raise or lower novelty ratings.

Hypothesis 11 . Subjective novelty will decline more rapidly over a sequence of identical stimuli than over a sequence of heterogeneous stimuli: there will be a steeper trend over the first 15 stimuli of sequence class (3) than over the fi rst 15 stimuli of sequence class (4).

Hypothesis 12 Subjective novelty will decline over a sequence of heterogeneous stimuli: there will be a significant downward trend over the first 15 stimuli of sequence class (4). This hypothesis is suggested by evidence (Berlyne, Craw, Salapatek, \& Lewis, 1963; Kratin, 1959) that novel stimuli, as they succeed one another, become less and less effective at intensifying or evoking an orientation reaction. In other words, novelty as such may lose its novelty value!

Table 4. Experiment 2

Data Relevant to Hypotheses 1, 3, 9, and 10

\begin{tabular}{cllllll} 
Hypothesis & Independent variable & Stimulus & Mean & Stimulus & Mean & $\mathrm{F}(\mathrm{df}=1 / 72)$ \\
\hline 1. & Time since last $X$ & $\mathrm{X}_{\mathrm{L}}(1)$ & 3.8 & $\mathrm{X}_{\mathrm{L}}(2)$ & 3.5 & $\mathrm{~ns}$ \\
3. & Prior appearance of $X$ & $\mathrm{X}_{\mathrm{L}}(1,2)$ & 3.6 & $\mathrm{X}_{\mathrm{L}}(3,4)$ & 4.2 & $3.5 *$ \\
9. & Number of kinds of prior stimuli & $\mathrm{X}_{\mathrm{L}}(3)$ & 4.4 & $\mathrm{X}_{\mathrm{L}}(4)$ & 4.0 & $\mathrm{~ns}$ \\
10. & Prefamiliarization & $\mathrm{X}_{\mathrm{L}}(\mathrm{F})$ & 3.3 & $\mathrm{X}_{\mathrm{L}}(\mathrm{NF})$ & 4.5 & $14.00 * *$
\end{tabular}

Two-tailed $p$ values: ${ }^{*} p<.1,{ }^{* *} p<.001$, ns - not significant. 


\section{Experimental design}

The $80 \mathrm{Ss}$ were divided into four prefamiliarized and four nonprefamiliarized groups of five men and five women. One prefamiliarized (F) and one nonprefamiliarized (NF) group had each of the four pairs of sequences shown in Table 3 .

This design permitted Hypotheses $1,5,6,8,9,11$, and 12 to be tested by within-Ss comparisons and Hypotheses 3 and 10 by between-Ss comparisons. It will be noted that stimuli differed from one another in both shape and color.

\section{Resulis}

The curves for the different sequence classes and phases, with and without prefamiliarization, are shown in Fig. 4.
Hypotheses 1, 3, 9, and 10 . Orthogonal contrasts testing the principal predictions from these hypotheses were extracted from an analysis of variance carried out on ratings of $\mathrm{X}_{\mathrm{L}}$ stimuli in all conditions and in both phases. The relevant data are displayed in Table 4.

It will be seen that, once again, Hypothesis 1 was not confirmed, despite the greater difference in the independent variable. Neither was Hypothesis 9. The difference pertaining to Hypothesis 3 was in the expected direction and attained a $p$ value of .1 . It will be recalled that this same hypothesis received some measure of confirmation in Experiment 1. Combining the significance levels for the two experiments, we obtain a $z$ value of 2.81 , for which $p<.01$. So we can regard Hypothesis 3 as

EXP. II

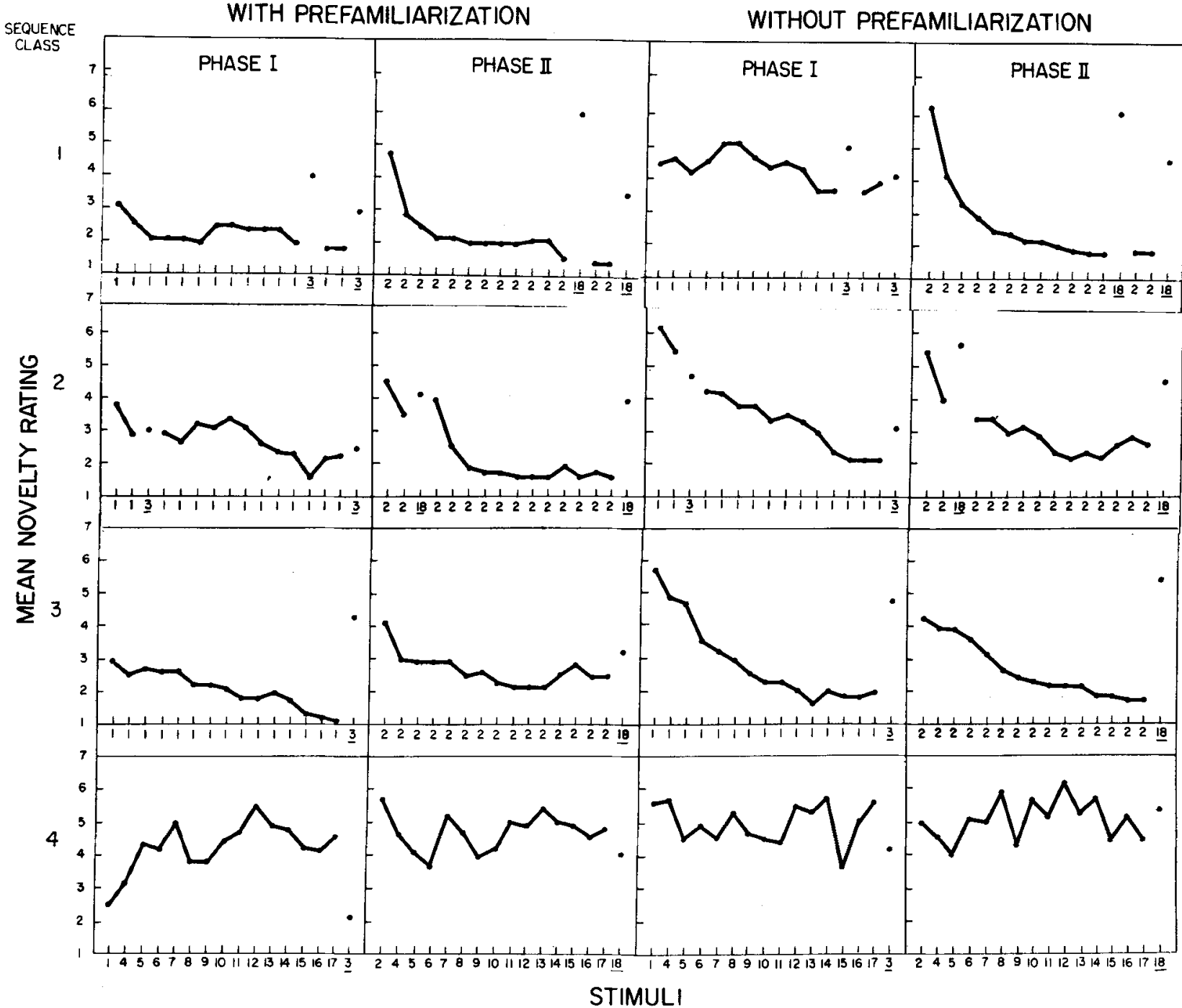

Fig. 4. Mean-novelty-rating curves from Experiment 2. 
confirmed. The mean rating was significantly higher without the prefamiliarization treatment than with it. This confirms Hypothesis 10 and shows that the effect of familiarizing $S$ with a set of stimuli is to lower their subjective novelty when they are encountered a short time later.

The mean rating was significantly higher in Phase II (4.3) than in Phase I (3.5) $(\mathrm{F}=8.64, \mathrm{df}=1 / 72, \mathrm{p}$ $<.005)$. This is difficult to interpret. It seems likely to have been due, in some way, to increased practice at using the scale, making Ss less reluctant to assign higher values. None of the interactions involving phases, presence or absence of prefamiliarization, and sequence classes was significant.

Hypothesis 5. The mean rating of $\mathrm{x}_{1}$ was significantly higher in sequence class (1) than in sequence class (2) (5.3 and 4.4, respectively; $F=7.94$, df $=1 / 36, p<.01)$. So Hypothesis 5 is confirmed. In Experiment 1, with a smaller difference in the independent variable, it was not confirmed. Hypothesis 10 also received further confirmation: the $\mathrm{X}_{1}$ mean was higher without (5.4) than with (4.3) prefamiliarization $(\mathrm{F}=4.22, \mathrm{df}=1 / 36, \mathrm{p}<.05)$. And the mean was once again higher in Phase II (5.5) than in Phase I (4.2) $(F=15.39, \mathrm{df}=1 / 36, \mathrm{p}<.001)$. Hypothesis 6 . In sequence classes (1) and (2), the mean rating of $X_{1}(4.8)$ was significantly higher than that of $X_{L}(3.6) \quad(F=24.00, d f=1 / 108, p<.001)$ so that Hypothesis 6 is confirmed, as in Experiment 1.

Hypothesis 8 The ratings of the 12 consecutive $Y$ items at the beginning of sequence class (1) declined with significant linear $(F=122.09, \mathrm{df}=1 / 396$, $\mathrm{p}<.001)$ and quadratic $(\mathrm{F}=19.86, \mathrm{df}=1 / 396, \mathrm{p}<.001$ ) components. The linear component was significantly steeper in Phase It than in Phase I $(F=46.87$, df $=1 / 396, p<.001$ ) and without than with prefamiliarization $(F=8.99, \mathrm{df}=1 / 396, \mathrm{p}<.005)$. (See Fig. 4).

The quadratic component was significantly greater in Phase II $(\mathrm{F}=39.32, \mathrm{df}=1 / 396, \mathrm{p}<.001)$. It was not affected significantly by prefamiliarization, but the interaction between phases and presence or absence of prefamiliarization was significant with respect to it $(F=8.86, \mathrm{df}=1 / 396, p<.005)$. As Fig. 4 shows, curvature was in evidence only in Phase II results, and, in that phase, it was more marked in the absence of prefamiliarization.

It will be remembered that, in Experiment 1 as well, the decline was rectilinear and gentle in Phase I but steeply curvilinear in Phase II. One of the reasons for introducing the prefamiliarization treatment in Experiment 2 was to test the possibility that this effect might have occurred because Ss did not know until the end of Phase I what kinds of stimuli were awaiting them and, consequently, were keeping higher ratings in reserve. The results just reported show that prefamiliarization did not eliminate this effect, which tends to exclude this explanation. So it seems likely in some other way to have been due to the difference in amount of experience of the task.

Hypothesis 11. A trend analysis was carried out on the ratings of 15 items preceding the final $x_{L}$ in sequence classes (3) and (4). These, it will be recalled, comprise presentations of the same stimulus in sequence class (3) and of heterogeneous stimuli in sequence class (4). The overall trend had a significant linear component $(F=28.26$, $d f=1 / 1080$, $\mathrm{p}<.001$ ) but not a significant quadratic component.

This linear component was, however, steeper in sequence class (3) than in sequence class (4) ( $F=$ $60.53, \mathrm{df}=1 / 1080, \mathrm{p}<.001$ ) so that Hypothesis 11 is confirmed. The quadratic component also varied significantly between the sequence classes (see Fig. $4-F=8.42$, df $=1 / 1080, p<.005)$. Prefamiliarization attenuated the linear component of the decline (F $=13.24, \mathrm{df}=1 / 1080, \mathrm{p}<.001$ ) but did not affect the quadratic component. With respect to the quadratic component, the interaction between phases and presence or absence of prefamiliarization was, however, significant $(\mathrm{F}=13.77, \mathrm{df}=1 / 1080, \mathrm{p}<.001)$.

Hypothesis 12. When the trend over the first 15 stimuli of sequence class (4) was examined, a significant rising linear component was found $(F=4.36$, $\mathrm{df}=1 / 540, \mathrm{p}<.05)$. This is contrary to the prediction from Hypothesis 12 of a downward trend, and so the hypothesis is not confirmed. The overall quadritic component was not significant, but the Phases by Prefamiliarization interaction was significunt with respect to the quadratic component $(F=14.03, \mathrm{df}=1 / 540, \mathrm{p}<.001)$. As can be seen in Fig. 4, appreciable curvature appeared only in the prefamiliarized group that had sequence class (4) in Phase I.

\section{DISCUSSIOH}

Taking the results of both experiments together, we find that eight hypotheses (Nos. 3, 4, 5, 6, 7, $8,10$, and 11$)$ have been confirmed and four $(1,2$, 9 , and 12) have not. It appears that the subjective novelty of a stimulus, $X$, is less when $X$ has been experienced before in the recent past than when it has not, less the second time $\mathbf{X}$ is experienced than the first time, and less when $S$ has been exposed at the start of the experiment to all the stimuli that are to be presented. It increases with the number of repetitions of another stimulus, $Y$, prior to first presentation of $X$, and with the number of properties in which $X$ differs from $Y$. It declines progressively when a stimulus is repeated. It declines more steeply over a series of consecutive or intermittent presentations of the same stimulus than over a series of heterogeneous stimuli with the same temporal distribution. But we have no evidence that it varies with the time since the last presentation of $X_{v}$ with the number of prior presentations of $X$ when that number exceeds one, 
and with the number of kinds of stimuli preceding the first presentation of $X$. And it seems to increase, rather than decline, over a sequence of heterogeneous stimuli.

A conclusion that may be of at least equal importance is that this simple scaling technique can have reasonable sensitivity and inter-S reliability when applied to novelty, as the smoothness of some of the curves in Figs. 2 and 4 (each of which was derived from $10 \mathrm{Ss}$ ) attests.

Whether or not the exploratory, psychophysiological, and other responses that have been found to vary with novelty are closely related to subjective novelty appraised in this way is a matter for future research. We have already, however, some hints that the answer may not always be affirmative. One is the finding that subjective novelty rose as heterogeneous stimuli succeeded one another, whereas, as mentioned above, GSR and EEG measures have been found to wane. Then, we obtained no evidence that the subjective novelty of a stimulus varies with the interval since $S$ was last exposed to that stimulus, at least within the range tested. But there is plenty of evidence that the power of a stimulus to attract exploratory responses increases with this variable (see Berlyne, 1960).

\section{References}

Attneave, F. Physical determinants of the judged complexity of shapes. J. exp. Psychol., 1957, 53, 221-227.

Berlyne, D. E. The arousal and satiation of perceptual curiosity in the rat. J. comp. physiol. Psychol., 1955, 48, 238-246.

Berdyne, D. E. Uncertainty and conflict: a point of contact between information theory and behavior theory. Psychol. Rev., 1957, 64, 329-339.

Berlyne, D. E. Conflict, arousal and curiosity. New York:'McGrawHill, 1960 .

Berlyne, D. E. Motivational problems raised by exploratory and epistemic behavior. In S. Koch (Ed.), Psychology-A study of a science, Vol. 5. New York: McGraw-Hill, 1963.

Berlyne, D. E. Curiosity and exploration. Science, 1966, 153, 25-33.

Berlyne, D. E., Craw, M. A., Salapatek, P. H., \& Lewis, J. L. Novelty, complexity. incongruity, extrinsic motivation and the GSR. J. exp. Psychol., 1963, 66, 560-567.

Berlyne, D. E., \& Lawrence, G. H. Effects of complexity and incongruity variables on GSR, investigatory behavior, and verbally expressed preference. J. gen. Psychol., 1964, 71, 21-45

Berlyne, D. E., McDonnell, P., Nicki, R. M., \& Paham, L. C. C. Effects of auditory pitch and complexity on EEG desynchronization and on verbally expressed judgments. Canad. J. Psychol. 1967, 21, 346-367.

Blough, D. S. The study of animal sensory processes by operant methods. In W. K. Honig (Ed.), Operant behavior. New York: Appleton-Century-Crofts, 1966.

Borresen, C. R., \& Lichte, W. H. Shape constancy: dependence upon stimulus familiarity. J. exp. Psychol., 1962, 63, 92-97.

Day. H. Evaluations of subjective complexity, pleasingness and interestingness for a series of random polygons varying in complexity. Percept. \& Psychophys., 1967, 2, 281-286.

Granit, R. Receptors and sensory perception. New Haven: Yale University Press, 1935.

Goldstein, A. G. Familiarity and apparent complexity of random shapes. J. exp. Psychol., 1961, 62, 594-597.

Karmel, B. Z. The effect of complexity, amount of contour, element size, and element arrangement on visual preference behavior in the hooded rat, domestic chick, and human infant. Unpublished Ph.D. dissertation, George Washington University, 1966.

Kratin, G. (Analysis of "indifferent" stimulation from the encephalogram in man). Fiziol. Zh. SSSR, 1959, 45 (1), 16-23.

Stevens, S. S., \& Volkmann, J. The relation of pitch and frequency: a revised scale. Amer. J. Psychol., 1940, 53, 329-353.

Stouffer, S. A. et al. The American soldier, 1 . Adjustment during amy life. Princeton: Princeton University Press, 1949.

Vanderplas, J.M., G Garvin, E. A. The association value of random shapes. J. exp. Psychol., 1959, 57, 155-163.

\section{Note}

1. Supported by research grant APB-73 from the National Research Council of Canada. Experiment 1 was reported by L. C. C. Parham in a thesis submitted in accordance with the requirements for the M. A. degree of the University of Toronto.

(Accepted for publication February 15, 1968.) 